\title{
High Prevalence of Anterior Pituitary Deficiencies after Cranial Radiation Therapy for Skull Base Meningiomas.
}

Perrine Raymond ( $\sim$ perrine.raymond@hotmail.fr)

Institut de Cancérologie de Lorraine

Marc Klein

Centre Hospitalier Universitaire de Nancy

Thomas Cuny

Hôpital de la Conception

Olivier Klein

Centre Hospitalier Universitaire de Nancy

Julia Salleron

Institut de Cancérologie de Lorraine

Valérie Bernier

Institut de Cancérologie de Lorraine

\section{Research Article}

Keywords: Skull base meningiomas, radiation therapy, pituitary deficiencies, Increase morbimortality

Posted Date: March 9th, 2021

DOI: https://doi.org/10.21203/rs.3.rs-244899/v1

License: (1) This work is licensed under a Creative Commons Attribution 4.0 International License. Read Full License

Version of Record: A version of this preprint was published at BMC Cancer on December 1st, 2021. See the published version at https://doi.org/10.1186/s12885-021-09045-3. 


\section{TITLE PLAGE:}

High prevalence of anterior pituitary deficiencies after cranial radiation therapy for skull base meningiomas.

Perrine Raymond, MD (1), Marc Klein, MD, PhD (2), Thomas Cuny, MD, PhD (3), Olivier Klein, MD, PhD (4), Julia Salleron, MSc (5), Valérie Bernier-Chastagner, MD (6).

(1) : MD, Institut de Cancérologie de Lorraine

(2) : MD, PhD, department of endocrinology, university hospital CHU de Nancy,

(3) : MD, PhD, Aix Marseille Univ, APHM, Inserm, MMG, department of Endocrinology, Hôpital de la Conception, Marseille, France

(4) : MD, PhD, department of neurosurgery, university hospital CHU de Nancy,

(5) : MSc, Department of biostatistics, Institut de Cancérologie de Lorraine, Université de Lorraine, F-54519, Vandoeuvre-les-Nancy, France

(6) : MD, Institut de Cancérologie de Lorraine, department of radiation therapy

Corresponding author :

Perrine Raymond

Institut de Cancérologie de Lorraine

6 avenue de Bourgogne, 54519 Vandoeuvre Les Nancy

Email: perrine.raymond@hotmail.fr

Phone number: +33673841286

Author responsible for statistical analyses:

Julia Salleron; j.salleron@nancy.unicancer.fr

Short running title: Hypopituitarism after skull base radiotherapy.

Conflicts of interest: none

Disclosures: none 


\section{ABSTRACT:}

Background: Cranial irradiation represents the first-line treatment proposed in skull base meningiomas. While cranial irradiation is associated with a high risk of secondary hypopituitarism, few studies focused on the specific location of skull base meningiomas. Methods: 52 adults receiving photon-beam therapy for skull base meningiomas between 1978 and 2014 in our Institution were included. Anterior pituitary (ACTH, FSH, $\mathrm{GH}, \mathrm{LH}, \mathrm{TSH}$ and prolactin) as well as corresponding peripheral hormones (8amCortisol, IGF-1, fT3, fT4, 17ßestradiol or testosterone) were biologically screened before radiotherapy (baseline), then yearly until March 2019. The pituitary gland (PG) was delineated on CT and the mean dose delivered to it was calculated. Results: Mean age at diagnosis was $56+/-14$ years. Median follow-up was 7 years. Up to $60 \%$ of patients developed at least $\geq 2$ pituitary deficiencies, 10 years after radiotherapy. Gonadotroph, thyrotroph, corticotroph and somatotroph deficiencies occurred in $37 \%, 28 \%, 18 \%$ and $15 \%$ of patients, respectively. Hyperprolactinemia was found in $13 \%$ of patients. None patient had only one pituitary deficiency. In the multivariate analysis, a delivered dose to the $P G \geq 50$ Gy or a meningioma size $\geq 40 \mathrm{~mm}$ significantly increased the risk of developing hypopituitarism. Conclusions: Over a long-term follow-up, cranial radiation therapy used in skull base meningiomas led to a high prevalence of hypopituitarism, further pronounced in case of tumor $\geq 4 \mathrm{~cm}$. These results advocate for an annual and prolonged follow-up of the pituitary functions in patients with irradiated skull base meningiomas. 


\section{KEY WORDS:}

Skull base meningiomas; radiation therapy; pituitary deficiencies; Increase morbimortality.

\section{BACKGROUND:}

Meningiomas are the most common benign intracranial tumors, with an incidence of 8.3 per 100.000 population between 2010 and 2014 , representing $36.6 \%$ of primary cerebral tumors(1). Surgery is recommended as the first-line treatment in most cases with high rate of progression-free survival ranging from $96 \%$ at 3 years to $93 \%$ at 5 years $(2,3)$. However, when meningiomas are located near to the nerves or blood vessels, like in the skull base, surgery is more limited and exposes the patient to a high risk of recurrence (4). In such cases, cranial irradiation is one of the best treatment options, however few datas focused on the potential onset of radiotherapy-induced pituitary deficiencies. If untreated, the latter have a negative impact on quality of life $(5,6)$.

Hypopituitarism has been shown to increase morbi-mortality (7), and at-risk patients therefore require a regular follow-up to both diagnose and treat the outcome of hormonal deficiency(ies). In our study, our aim was to retrospectively assess the rates of anterior pituitary deficiencies in a population of patients treated by cranial radiation therapy for a skull base meningioma.

\section{METHODS}

We retrospectively reviewed the records of patients treated between 1978 and 2014 in our institution (Institut de Cancérologie de Lorraine) for skull base meningiomas, anterior or medial localization, (either confirmed histologically or presumed) by cerebral radiation therapy involving the pituitary gland within the radiation field. All included patients were $\geq 18$ years of age with normal values for anterior pituitary axis upon neuroendocrine analysis before 
the initiation of radiotherapy protocol. Excluded patients were $<18$ years of age, had previously undergone radiosurgery, had no or abnormal results from neuroendocrine analysis before radiotherapy initiation, received hormone replacement therapy (like birth estroprogestative pill or menopausal treatment), or had chronic exposure to glucocorticoids)

\section{Endocrinology:}

Before the first cranial irradiation session, patients underwent an initial hormonal analysis, which was not necessarily performed in our center. This hormonal check-up was considered as the baseline and comprised anterior pituitary hormones (ACTH, FSH, GH, LH, TSH and prolactin) as well as corresponding peripheral hormones (8amCortisol, IGF-1, fT3, fT4, 17bestradiol or testosterone)

Neuroendocrine analyses tested all five of the axes involving the anterior pituitary gland: the corticotroph (ACTH and 8am-Cortisol), somatotroph (IGF-1 and GH), gonadotroph (LH, FSH, 17bestradiol or testosterone), thyrotroph (TSH, fT3, fT4), and lactotroph axis (Prolactin). The diagnosis of Hypopituitarism was considered when a deficiency of $\geq 1$ of the 5 axis was found and panhypopituitarism when all 5 axes were deficient. A dysfunction of the lactotroph axis was suspected on hyperprolactinemia.

Dysfunction were determined by comparison to normal values for each tested hormone or marker as follows:

For the corticotroph axis, adrenal insufficiency was based on low cortisol (less than $50 \mathrm{mcg} / \mathrm{L}$ or $138 \mathrm{nmol} / \mathrm{L}$ ) with an inappropriate (low or normal) ACTH levels.

For the somatotroph axis, a low IGF1 in the absence of renal insufficiency, malnutrition, hepatic dysfunction and unequilibrated insulin production was considered as GH deficiency. No dynamic test was performed and a low GH was not considered as GH deficiency due to the pulsatile nature of GH secretion. Nevertheless, a low GH alongside an inappropriate low IGF1 was considered at risk of GH deficiency. 
For the gonadotroph axis, follicle-stimulating (FSH) and luteinizing (LH) hormones as well as testosterone for men and estradiol for women were analyzed. For men, low testosterone with an inappropriate FSH or LH was considered as evidence of hypogonadism. For women, an inappropriately low or normal FSH with low estradiol was considered evidence of gonadotropin dysfunction (particularly in menopausal women).

For the thyrotroph axis, low T4L or T3L with inappropriately low or normal TSH, according to the assay reference range, was considered evidence of central hypothyroidism.

Finally, for the lactotroph axis, a very low level of prolactin (below the normal range) was in favor of a lactotroph deficiency, while hyperprolactinemia could be interpretated as the reflect of an hypothalamic dysfunction by lesion of dopaminergic neurons.

\section{Radiation technique:}

All patients underwent radiation using photon-beam therapy either as first-line treatment or following initial surgery (partial or total), with fractionated daily doses of 1.8 to 2 Gy, giving a total dose of 54 to $60 \mathrm{~Gy}$ (mean $54.1 \mathrm{~Gy}+/-1.6$ min $50 \mathrm{~Gy}$ max $60 \mathrm{~Gy}$ ). A cranial thermomask was fitted and a radiotherapy-planning computed tomography scan performed for all patients. The gross tumor volume (GTV) was defined as the radiographically visible tumor, usually with dural extension, or as the post-operative cavity. Clinical target volume (CTV) was defined with a margin of $1 \mathrm{~cm}$ around the GTV, adapted to the cerebral anatomy. A margin of $0.3 \mathrm{~cm}$ was added to obtain planning target volume (PTV)

Constraints at delineated organs-at-risk were respected, and the pituitary region was also delineated to minimize radiation-induced toxicity. During the treatment, patients underwent weekly consultations with a radiation oncologist to detect any early side effects. After treatment, patients were followed up once every 6 months during the first two years and then once annually, consisting of an MRI and complete neuroendocrine analysis.

\section{Statistical analysis:}


Quantitative parameters were described as the mean and standard deviation or as median and interquartile range according to the normality of the distribution, as assessed by the ShapiroWilk test. Qualitative parameters were expressed as frequency and percentage.

Cumulative incidence of each deficiency was described with the Kaplan Meier method and was expressed with 95\% confidence interval. Prognostic factors of at least one anterior pituitary deficiency were investigated by the Cox proportional hazard model in bivariate analyses. Quantitative variables were transformed into binary variables. The threshold corresponded to the value that maximized the Wald statistic value in the bivariate Cox model. Parameters with a p-value less than 0.05 were introduced in a multivariate model with backward selection. Results were expressed as hazard ratios and their 95\% confidence intervals.

Statistical analysis was performed using SAS software, version 9 (SAS Institute Inc., Cary, NC). The threshold for statistical significance was set to $\mathrm{p}<0.05$.

\section{RESULTS}

We identified from our institute database 200 patients with meningioma, 117 for whom it was located in anterior or medial skull base, treated by radiation between 1978 and 2014. A total of 52 patients with skull base meningioma who underwent cranial radiation therapy and subsequently neuroendocrine analysis follow-up were included (Flow chart, figure 1). 


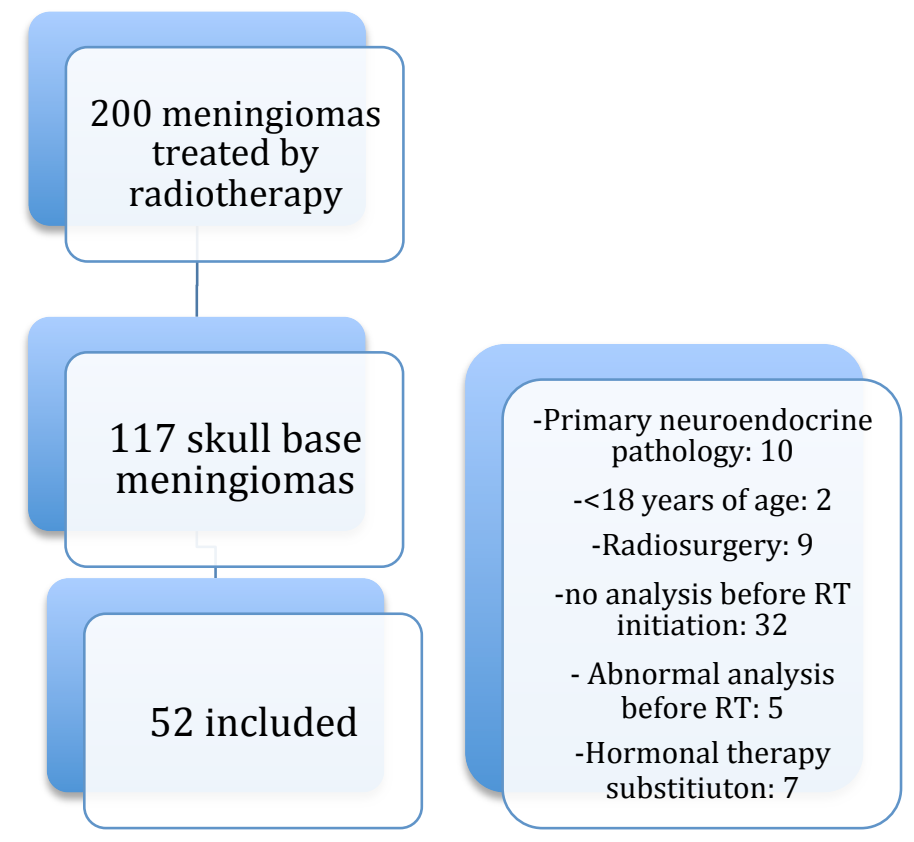

Figure 1 : Flow chart of patient inclusion and exclusion in the study Abbreviation : RT : Radiotherapy

The patient characteristics are listed in Table 1.

\begin{tabular}{|l|l|}
\hline Factor & Value \\
\hline Total number of patients & 52 \\
\hline Age at diagnosis (years) & $56.2+/-14.1$ \\
\hline $\begin{array}{l}\text { Sex } \\
\text { Memale } \\
\text { Male }\end{array}$ & $\begin{array}{l}42(80.8 \%) \\
10(19.2 \%)\end{array}$ \\
\hline Post menopause women & $26(50 \%)$ \\
\hline $\begin{array}{l}\text { BMI }(\mathrm{kg} / \mathrm{m} 2) \\
\text { <18,5 }\end{array}$ & $3(5.8 \%)$ \\
$\begin{array}{l}18,5-24,9 \\
>30\end{array}$ & $38(73 \%)$ \\
\hline Symptomatic disease manifestation & $6(11.5 \%)$ \\
\hline $\begin{array}{l}\text { Localization of skull base meningiomas: } \\
\text { Anterior } \\
\text { Medial }\end{array}$ & $5(9.7 \%)$ \\
\hline $\begin{array}{l}\text { Surgical resection before radiotherapy: } \\
\text { Gross total resection } \\
\text { Subtotal resection }\end{array}$ & $51(98.1 \%)$ \\
\hline
\end{tabular}




\begin{tabular}{|l|l|}
\hline Biopsy & $1(5.5 \%)$ \\
WHO tumor grade & \\
I & $\begin{array}{l}17(32.7 \%) \\
1(1.9 \%)\end{array}$ \\
\hline \multicolumn{1}{|c|}{ SI } & $27.8+/-13.9$ \\
\hline $\begin{array}{l}\text { Radiation therapy characteristics } \\
\text { IMRT }\end{array}$ & $52(100 \%)$ \\
Energy & $10(19.2 \%)$ \\
10X & $42(80.8 \%)$ \\
Overall treatment time (days) & $42.3+/-5.3$ \\
Number of fractions & $28.5+/-1.8$ \\
Total dose (Gy) & $54.1+/-1.6$ \\
Dose to HP axis (Gy) & $47+/-9.4$ \\
\hline
\end{tabular}

TABLE 1: Characteristics of the 52 analyzed patients

Results are presented as mean+/- standard deviation or by frequency and percentage Abbreviations:

BMI: Body Mass Index

WHO: World Health Organization

IMRT: Intensity Modulated Radiation Therapy

Gy: Gray

The median follow-up time was 7 years with an interquartile range of 5 to 10 years.

At least 2 pituitary deficiencies were present in $60.1 \%$ patients at 10 years, $95 \%$ confidence interval [40.8\%; 80.1\%] corresponding to a total of 22 patients as follows: 2 axis affected $(n=11), 3$ axis affected $(n=4), 4$ axis were affected $(n=3) . \quad$ A total of 4 patients had panhypopituitarism. No posterior pituitary deficiency was identified during the follow up.

The incidence of hypopituitarism and deficiency for each of the 5 axes during the follow-up period is shown in Figure 2 (graphic panel, Figure 2). 


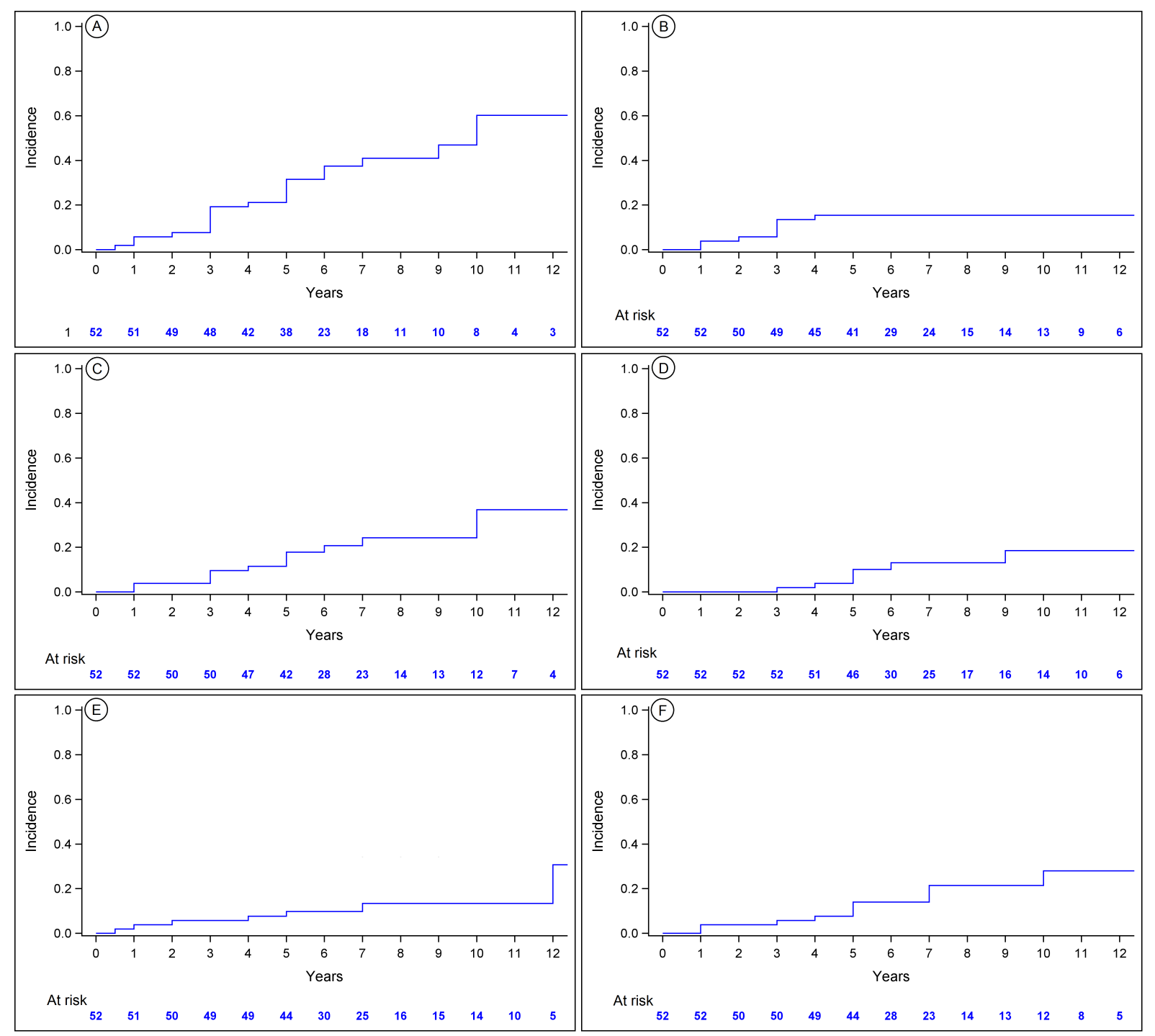

Figure 2 : Incidence of pituitary deficiency

A : at least one of the 5 axes

B : the corticotroph axis

$\mathrm{C}$ : the gonadotroph axis

$\mathrm{D}$ : the lactotroph axis

E : the somatotroph axis

$\mathrm{F}$ : the thyrotroph axis

At 10 years follow-up, the gonadotroph axis was the most affected with $36.9 \%$ [21.1\%; 59.1\%], followed by the thyrotroph axis $(28.0 \%[14.6 \% ; 49.4 \%])$, the corticotroph axis $(15.4 \%[6.7 \%$; $28.4 \%])$ and finally the least affected was the somatotroph axis $(13.4 \%[6 \% ; 28.3 \%])$. 
Hyperprolactinemia appears in $18.5 \%[8.5 \% ; 37.6 \%]$, without any real deficiency (no low prolactin was assessed). $2.3 \%$ of the patients with gonadotroph deficiency had also hyperprolactinemia.

Pituitary deficiency appeared at different timeline within the first years of follow-up with a progressive increase of incidence at 3 and 5 years. Indeed, at 3 years follow up; the corticotroph axis was the most affected with $13.5 \%$ at 3 years, $15.4 \%$ at 5 years and stagnation at $15.4 \%$ at 10 years.

The results are summarized in Table 2.

\begin{tabular}{|l|l|l|l|}
\hline & \multicolumn{3}{|c|}{ Follow-up (years) } \\
\hline $\begin{array}{l}\text { Hormonal axis } \\
\text { dysfunction n (\%) }\end{array}$ & \multicolumn{1}{|c|}{5} & \multicolumn{1}{|c|}{10} \\
\hline $\begin{array}{l}\text { At least one of the 5 } \\
\text { axes }\end{array}$ & $10 / 52(19.2 \%)$ & $16 / 39(31.5 \%)$ & $22 / 26(60.2 \%)$ \\
\hline Corticotroph & $7 / 52(13.5 \%)$ & $8 / 37(15.4 \%)$ & $8 / 17(15.4 \%)$ \\
\hline Somatotroph & $3 / 52(5.8 \%)$ & $5 / 35(9.8 \%)$ & $6 / 16(13.4 \%)$ \\
\hline Gonadotroph & $5 / 52(9.6 \%)$ & $9 / 37(17.8 \%)$ & $13 / 20(36.9 \%)$ \\
\hline Thyrotroph & $3 / 52(5.8 \%)$ & $7 / 35(14 \%)$ & $10 / 18(28 \%)$ \\
\hline Lactotroph & $1 / 52(1.9 \%)$ & $5 / 35(10.1 \%)$ & $7 / 17(18.5 \%)$ \\
\hline
\end{tabular}

TABLE 2 : Anterior pituitary dysfunction after cranial irradiation for skull base meningioma.

Prognostic factors of at least one anterior pituitary deficiency are presented in Table 3.

\begin{tabular}{|l|l|l|l|l|}
\hline \multicolumn{2}{|l|}{ Univariate analysis } & \multicolumn{2}{l|}{ Multivariate analysis } \\
\hline & $\begin{array}{l}\text { Hazard ratio and } \\
\text { 95\% confidence } \\
\text { interval }\end{array}$ & p-value & $\begin{array}{l}\text { Hazard ratio and } \\
\text { 95\% confidence } \\
\text { interval }\end{array}$ & p-value \\
\hline $\begin{array}{l}\text { Size of tumor (mm) } \\
\leq 40 \\
>40\end{array}$ & 1 & & 1 & \\
\hline $\begin{array}{l}\text { Mean dose to } \\
\text { pituitary (Gy) } \\
<50\end{array}$ & $2.98[1.03 ; 8.60]$ & 0.044 & $4.01[1.32 ; 12.16]$ & 0.014 \\
$\geq 50$ & 1 & & & \\
\hline $\begin{array}{l}\text { Age at diagnosis } \\
\text { (years) }\end{array}$ & $3.63[1.07 ; 12.30]$ & 0.039 & $2.68[1.11 ; 6.44]$ & 0.028 \\
\hline $\begin{array}{l}\text { Sex, } \\
\text { male } \\
\text { female }\end{array}$ & $0.99 ; 0.96 ; 1.03]$ & 0.741 & & \\
\hline
\end{tabular}




\begin{tabular}{|l|l|l|l|l|}
\hline $\begin{array}{l}\text { Surgery, } \\
\text { no } \\
\text { yes }\end{array}$ & 1 & & & \\
\hline
\end{tabular}

TABLE 3: Prognostic factors of at least one anterior pituitary deficiency.

In univariate analyses, the risk of hypopituitarism significantly increased when the size of tumor exceeded $40 \mathrm{~mm}$ (HR 2.98, 95\% CI [1.03; 8.60]) and when the mean dose delivered to the pituitary was $\geq 50$ Gy (HR 3.63, 95\% CI [1.07; 12.30]). They remained significant in multivariate analysis. Age at diagnosis, gender and surgery before radiation therapy were not predictive of deficiency.

\section{DISCUSSION}

In this study of 52 patients with skull base meningiomas, the incidence of pituitary dysfunctions after cranial irradiation was high, up to $60.1 \%$ of patients at 10 years of treatment. We observed that hypopituitarism could appear very early within the first years after treatment, with increasing frequency thereafter.

Our study has good reproducibility, with a very homogenous population: regarding the radiation techniques, all the patients were treated using photon-beam therapy. Moreover, analyses for all 5 pituitary hormonal axes were available for all included patients, with a significant long follow-up (12 years). Because of the presence of progesterone receptors in some meningiomas $(8,9)$, these tumors are mostly developed in women, which is the case in our population ( $80 \%$ of women).

In their study performed in 2005 on a general population of Northwestern Spain, Regal M. and al, (10) found a prevalence of 45.5/100 000 of hypopituitarism, 61\% of whom had pituitary tumors, which is very low compared to our prevalence of insufficiency. This supports the hypothesis of the role of cranial irradiation in the development of the observed pituitary hormonal axis deficiencies. 
Previous studies showed that cranial radiotherapy almost systematically induces pituitary dysfunction with a range ranging from 25 to $100 \%$, depending on the study considered (1114). One recent meta-analysis pooled 18 studies with a total of 813 patients who underwent cranial radiotherapy for head and nasopharynx tumors (15). Amongst the patients, 31 had a meningioma. A total of $66 \%$ patients developed hypopituitarism as follows: $45 \%$ with GH deficiency, 30\% with LH/FSH deficiency, 25\% with TSH deficiency, 22\% with ACTH deficiency and 34\% with hyperprolactinemia. The important variation of prevalence between studies may be due to heterogeneous population, including cerebral and nasopharyngeal tumors with very different prognoses compared to meningiomas. It may also be due to a higher radiation dose exposure, or an incomplete endocrine evaluation in some studies (analysis including the 5 hormonal axes were not available in all patients).

As such, to the best of our knowledge, few studies focused specifically on the risk of cranial irradiation-induced hypopituitarism for meningioma of the skull base. Most previous studies have involved cerebral tumors and nasopharyngeal tumors. One recent study of 74 patients treated for sellar or parasellar meningiomas, with a median follow up of 3 years, found that $20 \%$ developed a pituitary dysfunction(16) which is in line with our result $(19.2 \%$ at 3 years follow up) with thyrotroph and corticotroph axes being the most affected (24\% each); the gonadotroph axis was the least affected with a prevalence at $10 \%$ and the somatotroph axis was affected in $19 \%$. These differences may be explained by the fact that not all pituitary axes were studied for all patients (out of 74 patients, a somatotroph analysis was performed in only 16, and gonadotroph analysis in 31). Moreover, this group of patients was more heterogeneous than ours, with photon-beam therapy used in only 74\% compared to all patients in our study. Several studies have reported an increase in mortality due to hypopituitarism, underlining the need to screen patients following cranial irradiation. 
Concerning the effect on the pituitary axes, the gonadotroph axis was the most affected in our study, with a prevalence of $36.9 \%$ at 10 years. $2.3 \%$ of these patients presented hyperprolactinemia.

Regal $M$ and al (10) also found a higher prevalence for the gonadotroph axis among the axes affected, followed by the thyrotroph axis.

The least affected axis in our study was the somatotroph axis (13.4\%), which differs in comparison to other studies. Indeed, in their meta-analysis Appelman and al. (15) observed GH deficiency in $45 \%$ of cases, which correlates well with the more frequent studies on children that show the somatotroph axis to be the most sensitive axis $(17,18)$. Unlike adults, children are treated automatically regardless of initial signs of GH deficiency due to the important negative consequences on growth. Several hypotheses can be discussed to explain our findings of a lower prevalence of GH deficiency. First, in adults, GH cells are the most commonly found in the anterior pituitary gland and may explain why some loss of cells would go unnoticed, with GH production being compensated by the remaining cells (19). Second, in contrast to other patient series, our group of patients was very homogeneous. All were treated for meningiomas, which have a very good prognosis, and overall the general status was better among our population, with lower rates of malnutrition and organ deficiencies. Levels of IGF1 correlate with nutrition status, hepatic and renal homeostasis, and insulin sensitivity $(20,21)$. While the somatotroph axis appeared the least affected among our patients, analyses for most were carried out in an external laboratory with norms of GH and IGF1 that did not take age into consideration. New reference ranges used in laboratories as standard consider that pituitary hormone secretion is age-dependent (22). One limitation of our study is the lack of any dynamic test for example the insulin test to screen for corticotroph and somatotroph deficiencies (23-25). Such a test could be recommended in cases of discordance between clinical and laboratory tests or if adrenal analysis (cortisol) or IGF1 levels are low. Indeed, 
adrenal deficiency should be considered a real emergency. However, this dynamic test must be performed in a hospital setting and in the absence of contraindications (history of epilepsy, stroke and cardiac issues), due to the presence of unpleasant symptoms (in particular hypoglycemia).

Due to a large panel of symptoms associated with their deficiencies, corticotroph, thyrotroph and gonadotroph axes represent the 3 most important axes requiring rapid treatment in the event of a deficiency. In contrast, somatotroph deficiency is barely compensated in adults as associated symptoms tend to be rare but mainly because such treatment increases the risk of tumor progression. In our study, all patients were treated for corticotroph and thyreotroph deficiency at diagnosis. Gonadotroph axis was not treated because of the age of the patients ( $>50$ years at diagnosis).

We also found predictive factors of hypopituitarism. Indeed, a dose to the pituitary gland $\geq 50$ Gy or meningiomas measuring $\geq 40 \mathrm{~mm}$ were individually and significantly correlated with an increased risk of developing hypopituitarism. This concurs with earlier findings on skull base tumors by Pai et al in 2001 (14), who found that a minimum dose to the pituitary $\geq 50$ Gy significantly increased the risk of pituitary dysfunction. These authors also revealed a higher sensitivity to radiotherapy of the hypothalamus and recommended a maximum dose to this organ of $50 \mathrm{~Gy}$. Concerning the dose, Littley et al (12) in 1989 showed that hypopituitarism decreased with radiation doses $<20$ Gy on the pituitary gland, whereas a dose between 35-45 Gy increased the risk. We are unable to confirm or not these earlier data with results from our study since a very high proportion of pituitary doses were $\geq 50$ Gy (with a mean dose of 47 Gy and a range from15.9 to $54.5 \mathrm{~Gy})$.

In the light of these results and our findings, we believe a new study on a homogenous group of patients with skull base meningioma would be interesting to assess the impact of cranial irradiation on the hypothalamus versus the pituitary gland. 
Interestingly, P. Mehta and al. (27) reported, in a retrospective study, the importance of sparing the hippocampus and the hypothalamus during a whole brain radiotherapy, using a volumetric modulated arc therapy. They showed that a simultaneous dose reduction to the hippocampus and the hypothalamus area did not compromise the planning target volume (PTV) coverage and thereby could be more used in routine.

Moreover, Pai et al (14) also found that age $>40$ years and histological type of tumor were individually predictive of pituitary dysfunction, especially along the corticotroph and thyrotroph axes. Concordantly, Regal et al (10) found an 8 fold increase in risk of hypopituitarism among both sexes after 70 years of age, and a statistical difference between the age groups of 18-29 years and 30-49 years. We found no statistical differences in regard to these variables in our study, likely due to our patient group being highly homogenous with a mean age of 56.2 years $+/-14.1$.

The precise pathophysiology behind this radiotherapy-induced deficiency remains unclear however one well-described hypothesis involves necrosis. The finding of increased sensitivity to irradiation among hypothalamic cells may lead to us shedding some light on the causative mechanisms $(13,26)$.

In agreement with that shown previously (14), our retrospective study has highlighted a correlation between cerebral irradiation for skull base meningioma and risk of hypopituitarism with a dose-dependence $\geq 50$ Gy and a meningioma size $\geq 40 \mathrm{~mm}$ increasing this risk.

\section{CONCLUSIONS:}

To conclude, we observed a greater frequency of hypopituitarism among our patient population compared to the general population (10). We also found that such deficiencies manifest differently according to which of the 5 hormonal axes is affected; this could guide 
physicians in their clinical examination of patients followed-up after radiotherapy. An annual follow up is recommended on all 5 axes for a minimum of 12 years; indeed GH deficiency still appears after 12 years of follow up.

We also found a correlation between the risk of hypopituitarism and a dose to the pituitary gland $\geq 50$ Gy and meningiomas measuring $\geq 40 \mathrm{~mm}$. These could represent predictive factors and alert physicians to the need for very assiduous monitoring in such patients. In light of these results, a maximum dose of 45 Gy should be applied whenever possible to reduce the toxicity to the pituitary gland. Both hypothalamus and pituitary gland critically require careful delineation in the CT planning stage of radiotherapy.

Nevertheless, prospective studies would be necessary to prove the causal relationship between these factors. It would also be interesting to compare photon-beam and proton therapies and the mean doses to both the pituitary gland and the hypothalamus, neither of which is at present routinely delineated in our center.

Finally, the observed difference between prevalence in a general adult population and in our population, underlines the need for careful consideration of the risks to individual patients of hypopituitarism before cranial radiation therapy for skull base meningioma. We recommend adapting the course of action with regard to follow up procedure required according to the results of neuroendocrine analyses and predictive factors obtained before cranial radiation therapy, as proposed in our decisional tree (Figure 3). 


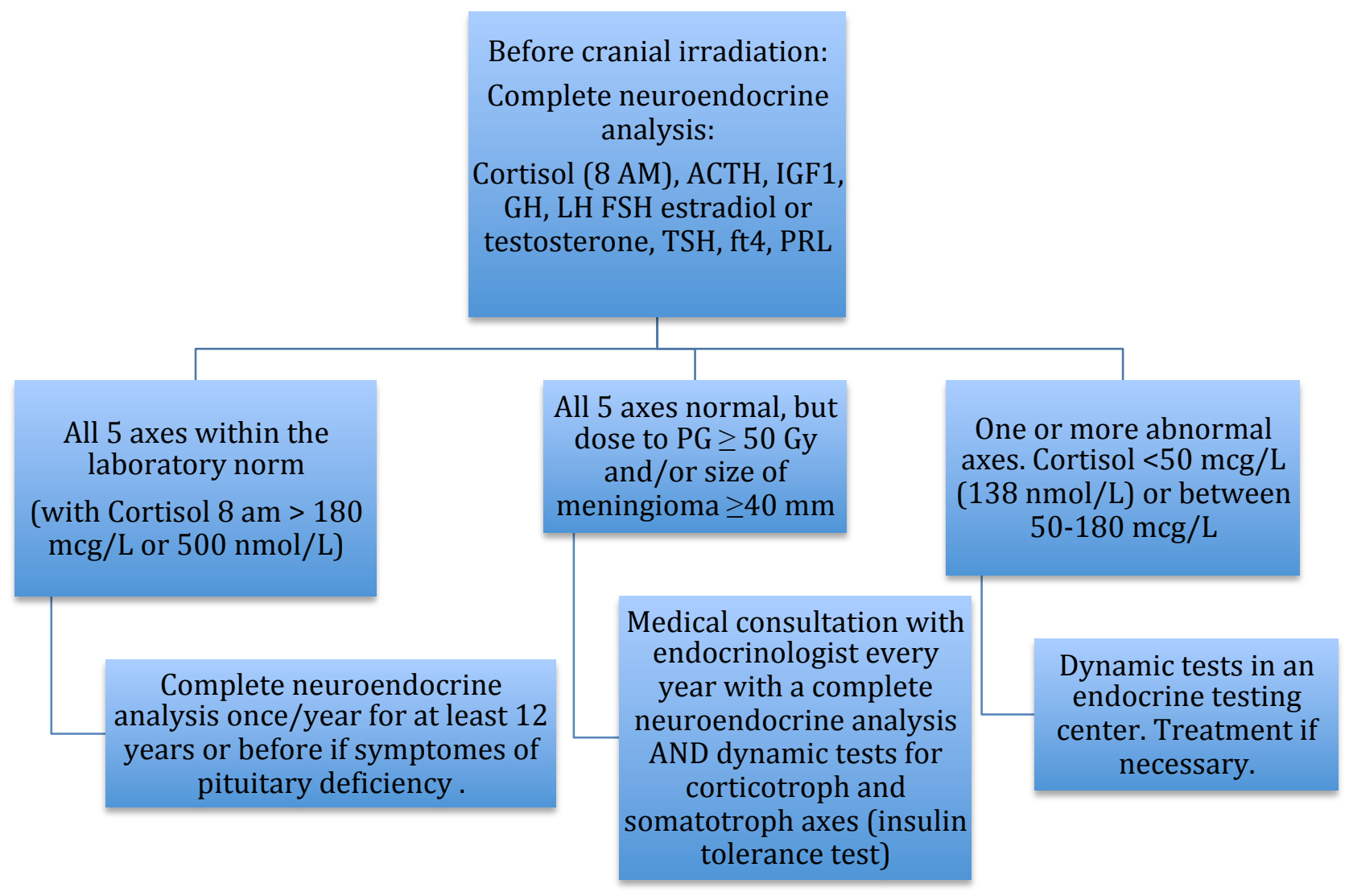

Figure 3 : Decisional tree on recommanded follow up procedure according to neuroendocrine analysis results and predictive factors.

Abbreviation : PG : pituitary gland 


\section{REFERENCES}

1. Buerki RA, Horbinski CM, Kruser T, Horowitz PM, James CD, Lukas RV. An overview of meningiomas. Future Oncol Lond Engl. 2018;14(21):2161-77.

2. Kessel KA, Fischer H, Oechnser M, Zimmer C, Meyer B, Combs SE. High-precision radiotherapy for meningiomas : Long-term results and patient-reported outcome (PRO). Strahlenther Onkol Organ Dtsch Rontgengesellschaft Al. nov 2017;193(11):921-30. 3. Dufour H, Muracciole X, Métellus P, Régis J, Chinot O, Grisoli F. Long-term tumor control and functional outcome in patients with cavernous sinus meningiomas treated by radiotherapy with or without previous surgery: is there an alternative to aggressive tumor removal? Neurosurgery. févr 2001;48(2):285-94; discussion 294-296.

4. Simpson D. THE RECURRENCE OF INTRACRANIAL MENINGIOMAS AFTER SURGICAL TREATMENT. J Neurol Neurosurg Psychiatry. févr 1957;20(1):22-39.

5. Brahimi Y, Antoni D, Srour R, Proust F, Cebula H, Labani A, et al. Méningiomes de la base du crâne : efficacité et tolérance clinique, efficacité radiologique et cinétique tumorale après radiothérapie. Cancer/Radiothérapie. 1 mai 2018;22(3):264-86.

6. Combs SE, Adeberg S, Dittmar J-O, Welzel T, Rieken S, Habermehl D, et al. Skull base meningiomas: Long-term results and patient self-reported outcome in 507 patients treated with fractionated stereotactic radiotherapy (FSRT) or intensity modulated radiotherapy (IMRT). Radiother Oncol J Eur Soc Ther Radiol Oncol. févr 2013;106(2):186-91.

7. Tomlinson JW, Holden N, Hills RK, Wheatley K, Clayton RN, Bates AS, et al. Association between premature mortality and hypopituitarism. West Midlands Prospective Hypopituitary Study Group. Lancet Lond Engl. 10 févr 2001;357(9254):425-31.

8. Vadivelu S, Sharer L, Schulder M. Regression of multiple intracranial meningiomas after cessation of long-term progesterone agonist therapy. J Neurosurg. mai 2010;112(5):920-4.

9. Wiemels J, Wrensch M, Claus EB. Epidemiology and etiology of meningioma. J Neurooncol. sept 2010;99(3):307-14.

10. Regal M, Páramo C, Sierra SM, Garcia-Mayor RV. Prevalence and incidence of hypopituitarism in an adult Caucasian population in northwestern Spain. Clin Endocrinol (Oxf). déc 2001;55(6):735-40.

11. Kyriakakis N, Lynch J, Orme SM, Gerrard G, Hatfield P, Loughrey C, et al. Pituitary dysfunction following cranial radiotherapy for adult-onset nonpituitary brain tumours. Clin Endocrinol (Oxf). mars 2016;84(3):372-9.

12. Littley MD, Shalet SM, Beardwell CG, Ahmed SR, Applegate G, Sutton ML. Hypopituitarism following external radiotherapy for pituitary tumours in adults. Q J Med. févr 1989;70(262):145-60.

13. Littley MD, Shalet SM, Beardwell CG. Radiation and hypothalamic-pituitary function. Baillieres Clin Endocrinol Metab. mars 1990;4(1):147-75.

14. Pai HH, Thornton A, Katznelson L, Finkelstein DM, Adams JA, Fullerton BC, et al. Hypothalamic/pituitary function following high-dose conformal radiotherapy to the base of skull: demonstration of a dose-effect relationship using dose-volume histogram analysis. Int J Radiat Oncol Biol Phys. 15 mars 2001;49(4):1079-92.

15. Appelman-Dijkstra NM, Kokshoorn NE, Dekkers OM, Neelis KJ, Biermasz NR, Romijn JA, et al. Pituitary dysfunction in adult patients after cranial radiotherapy: 
systematic review and meta-analysis. J Clin Endocrinol Metab. août 2011;96(8):2330-40. 16. Lamba N, Bussiere MR, Niemierko A, Abedi P, Fullerton BC, Loeffler JS, et al. Hypopituitarism following Cranial Irradiation for Meningiomas: A single-institution experience. Pract Radiat Oncol. 4 févr 2019;

17. Ogilvy-Stuart AL, Clark DJ, Wallace WH, Gibson BE, Stevens RF, Shalet SM, et al. Endocrine deficit after fractionated total body irradiation. Arch Dis Child. sept 1992;67(9):1107-10.

18. Vatner RE, Niemierko A, Misra M, Weyman EA, Goebel CP, Ebb DH, et al. Endocrine Deficiency As a Function of Radiation Dose to the Hypothalamus and Pituitary in Pediatric and Young Adult Patients With Brain Tumors. J Clin Oncol Off J Am Soc Clin Oncol. 1 oct 2018;36(28):2854-62.

19. Masson E. Anatomie et histologie de l'hypophyse humaine [Internet]. EMConsulte. [cité 7 sept 2019]. Disponible sur: https://www.emconsulte.com/article/60787/anatomie-et-histologie-de-l-hypophyse-humaine 20. Franco L, Williams FMK, Trofimov S, Malkin I, Surdulescu G, Spector T, et al. Assessment of age-related changes in heritability and IGF-1 gene effect on circulating IGF-1 levels. Age [Internet]. juin 2014 [cité 7 sept 2019];36(3). Disponible sur: https://www.ncbi.nlm.nih.gov/pmc/articles/PMC4082604/

21. Kwan AYM, Hartman ML. IGF-I measurements in the diagnosis of adult growth hormone deficiency. Pituitary. 2007;10(2):151-7.

22. Friedrich N, Krebs A, Nauck M, Wallaschofski H. Age- and gender-specific reference ranges for serum insulin-like growth factor I (IGF-I) and IGF-binding protein-3 concentrations on the Immulite 2500: results of the Study of Health in Pomerania (SHIP). Clin Chem Lab Med. 2010;48(1):115-20.

23. Fish HR, Chernow B, O'Brian JT. Endocrine and neurophysiologic responses of the pituitary to insulin-induced hypoglycemia: a review. Metabolism. août 1986;35(8):763-80.

24. Consensus guidelines for the diagnosis and treatment of adults with growth hormone deficiency: summary statement of the Growth Hormone Research Society Workshop on Adult Growth Hormone Deficiency. J Clin Endocrinol Metab. févr 1998;83(2):379-81.

25. Erturk E, Jaffe CA, Barkan AL. Evaluation of the Integrity of the HypothalamicPituitary-Adrenal Axis by Insulin Hypoglycemia Test. J Clin Endocrinol Metab. 1 juill 1998;83(7):2350-4.

26. Shalet SM. Radiation and Pituitary Dysfunction. N Engl J Med. 14 janv 1993;328(2):131-3.

27. Mehta P, Janssen S, Fahlbusch FB, Schmid SM, Gebauer J, Cremers F, et al. Sparing the hippocampus and the hypothalamic- pituitary region during whole brain radiotherapy: a volumetric modulated arc therapy planning study. BMC Cancer. 30 juin 2020;20(1):610. 
LIST OF ABBREVIATIONS :

ACTH : Adrenocorticotrophic Hormone

BMI : Body Mass Index

CT : Computarized Tomography

CTV : Clinical Target Volume

FSH : Follicle-Stimulating Hormone

fT3 : Free Tri-iodothyronine

fT4 : Free Thyroxine

GH : Growth Hormone

GTV : Gross Tumor Volume

Gy : Gray

HR : Hazard Ratio

IGF1 : Insulin Growth Factor 1

IMRT : Intensity Modulated Radiotherapy

LH : Luteinizing Hormone

MRI : Magnetic Resonance Imagery

PG : Pituitary Gland

PTV : Planning Target Volume

RT : Radiotherapy

TSH : Thyroid Stimulating Hormone

WHO : World Health Organization 


\section{DECLARATIONS}

\section{Ethics approval and consent to participate :}

Administrative permission was acquired to access data used in the research.

The analysis was not an intervention study. The study was approved by the ethics committee of the Institut de Cancerologie de Lorraine.

The study was conducted in accordance with the principles laid out in the Declaration of Helsinki and in accordance with the principles of Good Clinical Practice.

According to the CNIL MR004 compliance declaration, all patients are informed of the potential retrospective use of their clinical data for research purpose and of their right to refuse. Individual written consent was consequently waived in light of those elements.

Consent for publication : not applicable.

Availability of data and materials : All data generated or analysed during this study are included in this published article.

Competing interests : all authors declare that they have no competing interests.

Funding: None.

Authors' contributions : R.P and B.V made substantial contributions to the conception, interpreted the patient data and drafted the work. S.J had made substantial contributions to acquisition of data. B.V, C.T, K.M and K.O made substantial contributions to the conception and drafted the work. S.J made substantial contributions to the conception, analyzed the data and was a contributor in writing the manuscript. All authors approved and reviewed the final manuscript.

Acknowledgements : Not applicable.

\section{Authors' informations :}

(1) : MD, Institut de Cancérologie de Lorraine

(2) : MD, PhD, department of endocrinology, university hospital CHU de Nancy,

(3) : MD, PhD, Aix Marseille Univ, APHM, Inserm, MMG, department of Endocrinology, Hôpital de la Conception, Marseille, France

(4) : MD, PhD, department of neurosurgery, university hospital CHU de Nancy,

(5) : MSc, Department of biostatistics, Institut de Cancérologie de Lorraine, Université de Lorraine, F-54519, Vandoeuvre-les-Nancy, France

(6) : MD, Institut de Cancérologie de Lorraine, department of radiation therapy 
Figures

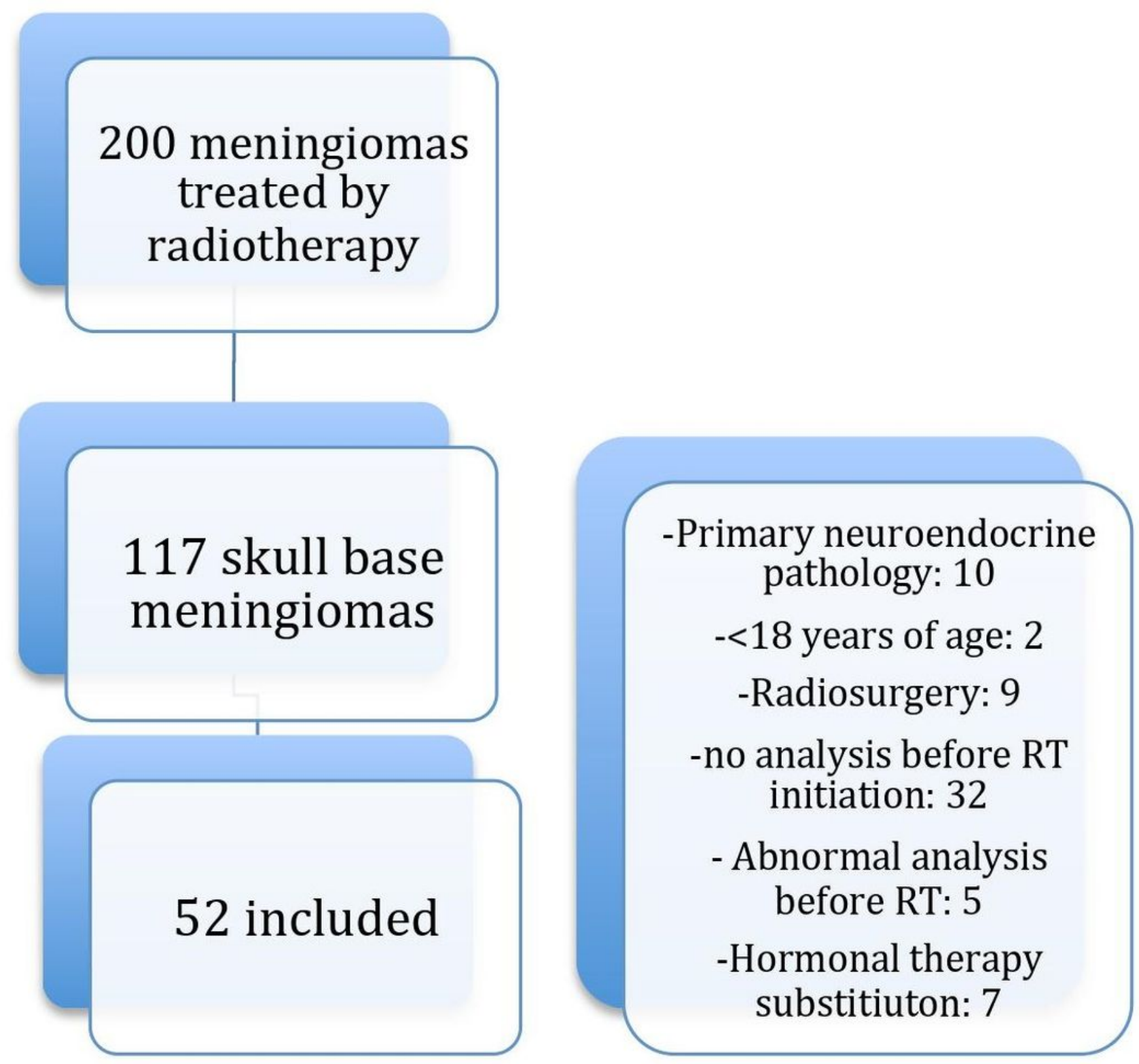

Figure 1

Flow chart of patient inclusion and exclusion in the study Abbreviation : RT : Radiotherapy 

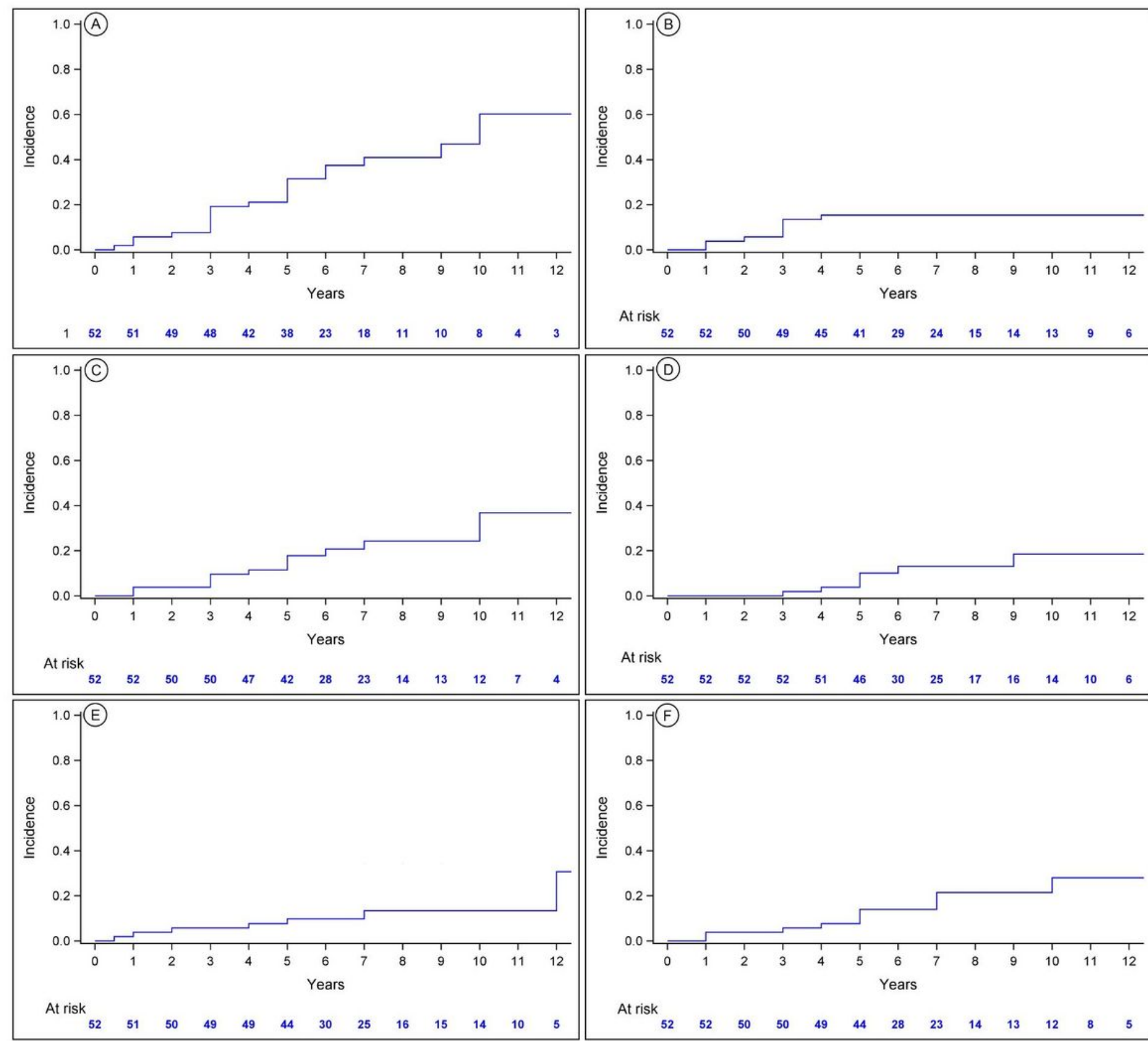

At risk

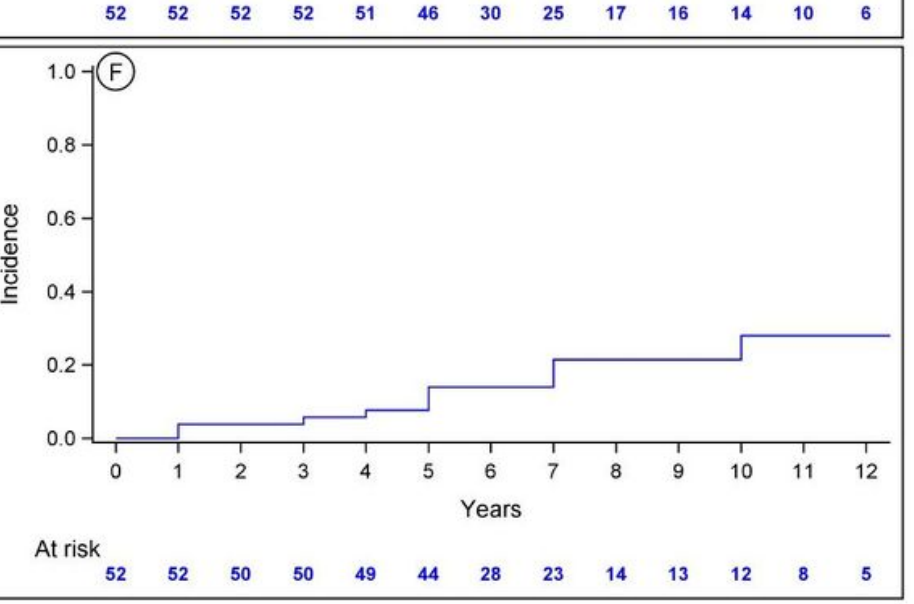

\section{Figure 2}

Incidence of pituitary deficiency $A$ : at least one of the 5 axes $B$ : the corticotroph axis $C$ : the gonadotroph axis $\mathrm{D}$ : the lactotroph axis 


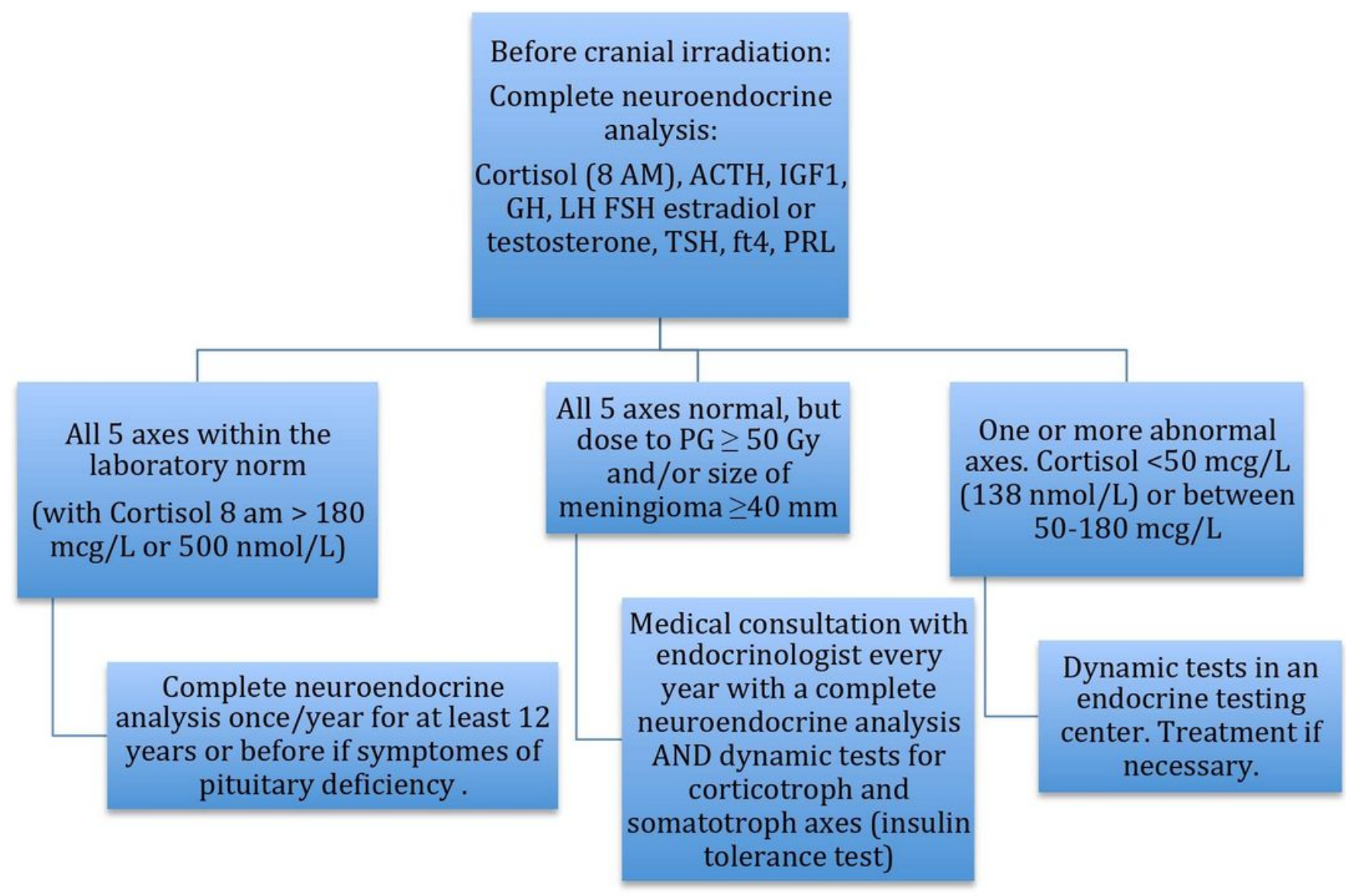

\section{Figure 3}

Decisional tree on recommanded follow up procedure according to neuroendocrine analysis results and predictive factors. Abbreviation : PG : pituitary gland 